\title{
Determinants of place of death: a population-based retrospective cohort study
}

\author{
Jyothi Jayaraman ${ }^{1,3^{*}}$ and KS Joseph ${ }^{2}$
}

\begin{abstract}
Background: As Canada's population ages, the location of end of life care (whether at home, extended care facility or hospital) may change depending on the location of death. We carried out a study to identify determinants of the place of death.

Methods: Data on deaths in British Columbia between 2004 and 2008 were obtained from the Vital Statistics Agency. Place of death was categorized into home, extended care facility, hospital or other. Logistic regression analyses were used to estimate the effects of age, sex, marital status, residence, place of birth and cause of death on place of death using adjusted odds ratios and 95\% confidence intervals (95\% Cl).

Results: Of the 153,111 deaths in the study, $16.5 \%$ occurred at home, $29.0 \%$ in extended care, $51.0 \%$ in hospital and $3.5 \%$ occurred elsewhere. Male deaths were less likely to occur in extended care as compared with female deaths (odds ratio $0.73,95 \% \mathrm{Cl} 0.71-0.75$ ). Age (odds ratio $3.31,95 \% \mathrm{Cl} 3.19-3.45$ for those for $\geq 90$ vs $70-79$ years), marital status (odds ratio 1.42, 95\% Cl 1.38-1.47 widowed vs married), residence (odds ratio $0.80,95 \% \mathrm{Cl} 0.76-0.83$ rural vs Vancouver), place of birth (odds ratio 0.80, 95\% Cl 0.75-0.86 China vs Canada) and cause of death (odds ratio $3.91,95 \% \mathrm{Cl} 3.69-4.13$ dementia vs cancer) were also associated with death in extended care.
\end{abstract}

Conclusions: Information on determinants of place of death can inform public health policy regarding care at the end of life and make resource allocation more efficient.

Keywords: Palliative care, Death, Home, Immigrants, Canada

\section{Background}

In 1950, approximately $50 \%$ of deaths in Canada occurred in hospital. This rate increased steadily and peaked in 1994 when about $81 \%$ of Canadian deaths occurred in hospital [1]. There has been a steady and sharp decline in hospital deaths since and approximately $61 \%$ of deaths in Canada occurred in hospital in 2004 [2]. Meanwhile, the percentage of deaths occurring at home has remained relatively constant in recent years, while the proportion of deaths in extended care facilities has increased substantially over the last decade. In 2009, about 30,000 people died in British Columbia, with the majority of deaths occurring in hospital (about 54\%), while the rest occurred

\footnotetext{
* Correspondence: jojrmn@gmail.com

'Division of Palliative Care, Department of Family Medicine, University of British Columbia, Vancouver, BC, Canada

${ }^{3}$ Vancouver General Hospital, 899 12th Avenue W, Vancouver, BC V5Z 1M9, Canada

Full list of author information is available at the end of the article
}

at home (16\%), in extended care facilities $(27 \%)$ and elsewhere [3].

Rates of death in hospital, at home and in extended care vary across Canada, with place of death influenced by demographic and sociologic factors such as age, sex and urban versus rural residence [4]. This issue has implications for public health policy given recent changes in the Canadian population including its ageing and changing ethnic composition. A better understanding of where specific subgroups of people die has implications for resource allocation for end of life care services in hospitals, in long term care facilities and in the community.

A recent study examined the effect of some of these determinants in Western Canada [5]. However, variations in recording of place of death among the different provinces did not permit a sufficiently detailed exploration of the independent determinants associated with place of death. We therefore carried out a study to quantify the independent contributions of various determinants of




place of death in British Columbia. Determinants of interest included age, gender, marital status, urban versus rural residence, place of birth and cause of death. We were particularly interested in associations with death in extended care facilities and at home.

\section{Methods}

End of life care in British Columbia is delivered in different locations, by different teams, with relatively good integration in the delivery of patient care. At the provincial level, all patients with less than 6 months life expectancy are enrolled in the British Columbia Palliative Care Benefits Program which entitles them to receive medications, equipment and home support. In the tertiary care hospitals there are Palliative Care Units, and a Palliative Care consult team for patients in other parts of hospital with palliative care needs. There are free-standing hospices across the province for more stable patients. The homehospice program is integrated with the community home care program and the latter provides home and nursing support to patients at home. Clinical nurse specialists in palliative care and palliative care physicians provide support to the primary care physicians and nurses in the community. There is also a 24 hour toll free phone line, staffed by palliative care specialists, for physicians in remote areas with no direct access to palliative care specialists.

Our study was restricted to vital statistics data and we studied all adult deaths ( $\geq 19$ years of age) in British Columbia for the years 2004 to 2008. Information about these deaths was obtained from the Vital Statistics Agency of British Columbia, which compiled this data from death registrations. The single underlying cause of death, coded using the International Classification of Diseases 10th revision (ICD-10), was based on the hierarchical cause of death information in the death registration [6,7].

Our study design and analysis used the proportionate mortality method to study associations between the determinants of interest and place of death. This study design is best conceptualized as a population-based case control study, with instances of a particular type of death (e.g., home death) treated as a case and an instance of another type of death serving as a control [8,9]. Cases were defined by the specific place of death and separate analyses were carried out to determine the determinants of home death, death in extended care and hospital death. The determinants of interest included age at death $(<50$, $50-59,60-69,70-79,80-89$ and $\geq 90$ years), sex (male and female), marital status (married, never married, widowed and other, with the latter including separated, divorced and common law status), residence status (Metro Vancouver, Victoria, other urban and rural residence), place of birth (Canada, Europe, USA, China, India, Hong Kong, Philippines and other) and the underlying cause of death. The distinction between residence in an urban versus a rural area was made using postal codes [10]. The name of the city or town where death occurred was used to further categorize urban locations into Vancouver, Victoria and other urban areas.

The single underlying cause of death coded in the death registration was categorized into one of 6 leading causes of death [3] and included malignant neoplasms (ICD-10 codes C00-C97), cardiovascular disease (I00-I51), cerebrovascular disease (I60-I69), chronic obstructive pulmonary disease (COPD, J40-J44), pneumonia/influenza (J09-J181, J188, J189), vascular/senile dementia (F01-F03, G30-G32) and other causes.

The relation between each determinant and the place of death was examined and rates of death at home, hospital and extended care were calculated for each category of each determinant. Relationships between determinants and place of death were expressed using odds ratios with 95\% confidence intervals (incidence density ratios technically, given the case control study design $[8,9])$. P values were used to guide inference and a two-sides $\mathrm{P}$ value of $<0.05$ was considered statistically significant. Logistic regression was used to estimate the independent effects of each determinant with the final model including variates based on all determinants of interest. Ethics approval was obtained from the University of British Columbia Clinical Research Ethics Board.

\section{Results}

There were 153,111 adult deaths in British Columbia between 2004 and 2008. Of these, 25,241 (16.5\%) occurred at home, 44,349 (29.0\%) occurred in extended care facilities, 78,161 (51.0\%) occurred in hospital and 5,360 (3.5\%) occurred elsewhere. Table 1 shows the characteristics of the decedents by place of death. The proportion of home deaths decreased with age, while the proportion of deaths in extended care facilities was highest among deaths $\geq 90$ years. The proportions of deaths in hospital were lowest at the extremes of age. The proportion of female deaths that occurred at home was lower than the same proportion among males, while the reverse was true for deaths in extended care facilities. Among deaths of people in rural areas, home deaths were more frequent, while deaths in extended care were less frequent compared with deaths in urban locations. Similarly, place of death differed by marital status, place of birth and cause of death (Table 1 ).

Table 2 shows the crude and adjusted odds ratios between person characteristics and home deaths. Deaths of people aged $<50,50-59$ and $60-69$ years were more likely to occur at home than deaths of people at 70-79 years of age. Conversely, deaths of people aged 80-89 and $\geq 90$ years were less likely to occur at home than deaths of people 70-79 years. Male deaths were more likely to occur at home than female deaths. Deaths among never married people were more likely to occur at home 
Table 1 Characteristics of decedents by place of death, British Columbia, Canada, 2004 to 2008

\begin{tabular}{|c|c|c|c|c|c|c|c|c|c|}
\hline \multirow[t]{2}{*}{ Characteristic } & \multicolumn{2}{|c|}{ Home } & \multicolumn{2}{|c|}{ Extended care } & \multicolumn{2}{|c|}{ Hospital } & \multicolumn{2}{|c|}{ Other } & \multirow[t]{2}{*}{ Tota } \\
\hline & No. & $\%$ & No. & $\%$ & No. & $\%$ & No. & $\%$ & \\
\hline Age (years) $<50$ & 3,181 & 28.7 & 761 & 6.9 & 4,498 & 40.6 & 2,639 & 23.8 & 11,079 \\
\hline $50-59$ & 3,681 & 28.6 & 1,596 & 12.4 & 6,620 & 51.5 & 955 & 7.4 & 12,852 \\
\hline $60-69$ & 4,561 & 23.8 & 2,986 & 15.6 & 10,847 & 56.7 & 739 & 3.9 & 19,133 \\
\hline $70-79$ & 6,040 & 17.7 & 7,576 & 22.3 & 19,868 & 58.4 & 556 & 1.6 & 34,040 \\
\hline $80-89$ & 5,919 & 11.8 & 18,155 & 35.8 & 26,331 & 51.8 & 384 & 0.8 & 50,789 \\
\hline$\geq 90$ & 1,859 & 7.4 & 13,275 & 52.6 & 9,997 & 39.6 & 87 & 0.3 & 25,218 \\
\hline Sex - Female & 10,226 & 13.7 & 26,865 & 36.0 & 36,249 & 48.6 & 1,238 & 1.7 & 74,578 \\
\hline Male & 15,015 & 19.1 & 17,484 & 22.3 & 41,912 & 53.4 & 4,122 & 5.3 & 78,533 \\
\hline Marital status - Married & 10,865 & 17.5 & 13,527 & 21.8 & 35,949 & 57.8 & 1,824 & 2.9 & 62,165 \\
\hline Never married & 3,574 & 24.2 & 3,057 & 20.7 & 6,357 & 43.1 & 1,777 & 12.0 & 14,765 \\
\hline Widowed & 6,116 & 11.0 & 23,144 & 41.7 & 25,753 & 46.4 & 495 & 0.9 & 55,508 \\
\hline Other & 4,686 & 22.7 & 4,621 & 22.4 & 10,102 & 48.9 & 1,264 & 6.1 & 20,673 \\
\hline Residence - Vancouver & 8,813 & 14.6 & 16,503 & 27.3 & 33,817 & 55.8 & 1,430 & 2.4 & 60,563 \\
\hline Victoria & 2,513 & 18.4 & 5,381 & 38.9 & 5,621 & 40.7 & 287 & 2.1 & 13,563 \\
\hline Other city & 9,966 & 16.8 & 18,410 & 31.1 & 28,437 & 48.0 & 2,480 & 4.2 & 59,293 \\
\hline Rural & 3,924 & 20.2 & 4,055 & 20.9 & 10,286 & 52.9 & 1,163 & 6.0 & 19,428 \\
\hline Birth country - Canada & 17,399 & 17.0 & 29,445 & 28.8 & 51,357 & 50.3 & 3,988 & 3.9 & 102,189 \\
\hline Europe & 4,941 & 15.7 & 10,424 & 33.1 & 15,564 & 49.4 & 606 & 1.9 & 31,535 \\
\hline USA & 646 & 16.7 & 1,230 & 31.8 & 1,810 & 46.8 & 178 & 4.6 & 3,864 \\
\hline China & 459 & 9.4 & 1,260 & 25.9 & 3,067 & 63.1 & 75 & 1.5 & 4,861 \\
\hline Hong Kong & 97 & 13.5 & 170 & 23.7 & 428 & 59.7 & 22 & 3.1 & 717 \\
\hline India & 458 & 16.2 & 314 & 11.1 & 1,917 & 67.6 & 146 & 5.2 & 2,835 \\
\hline Philippines & 133 & 15.5 & 156 & 18.2 & 542 & 63.2 & 27 & 3.2 & 858 \\
\hline Other & 1,108 & 17.7 & 1,350 & 21.6 & 3,476 & 55.6 & 318 & 5.1 & 6,252 \\
\hline Cause of death - Cancer & 8,034 & 18.7 & 12,197 & 28.3 & 22,530 & 52.4 & 271 & 0.6 & 43,032 \\
\hline Cardiovascular & 7,324 & 21.1 & 9,022 & 26.1 & 17,411 & 50.1 & 984 & 2.8 & 34,741 \\
\hline Cerebrovascular & 633 & 5.6 & 4,174 & 36.7 & 6,507 & 57.3 & 51 & 0.5 & 11,365 \\
\hline COPD & 820 & 12.4 & 1,779 & 27.0 & 3,950 & 60.0 & 40 & 0.6 & 6,589 \\
\hline Pneumonia/Influenza & 244 & 5.6 & 1,665 & 38.0 & 2,439 & 55.7 & 33 & 0.8 & 4,381 \\
\hline Dementia & 229 & 2.6 & 6,532 & 75.2 & 1,910 & 22.0 & 12 & 0.1 & 8,683 \\
\hline Other & 7,957 & 13.0 & 8,980 & 20.3 & 23,414 & 52.8 & 3,969 & 9.0 & 44,320 \\
\hline Year of death - 2004 & 5,070 & 17.1 & 7,988 & 26.9 & 15,554 & 52.4 & 1,051 & 3.5 & 29,633 \\
\hline 2005 & 5,065 & 16.8 & 8,258 & 27.5 & 15,639 & 52.0 & 1,107 & 3.7 & 30,069 \\
\hline 2006 & 5,029 & 16.5 & 9,176 & 30.1 & 15,263 & 50.1 & 1,023 & 3.4 & 30,491 \\
\hline 2007 & 5,043 & 16.2 & 9,709 & 31.3 & 15,236 & 49.1 & 1,069 & 3.4 & 31,057 \\
\hline 2008 & 5,034 & 15.8 & 9,218 & 29.0 & 16,469 & 51.7 & 1,110 & 3.5 & 31,831 \\
\hline
\end{tabular}

compared with deaths among the married. Comparisons by residence status showed that deaths in Victoria, other urban areas and rural areas were more likely to occur at home than deaths in Vancouver. Deaths from cardiovascular disease were more likely to occur at home compared with deaths from cancer, whereas deaths from cerebrovascular disease, Chronic Obstructive Pulmonary
Disease (COPD), pneumonia/influenza, dementia and other causes were less likely to occur at home than cancer deaths. Compared with deaths in 2004, deaths in subsequent years were less likely to occur at home.

The crude and adjusted associations between person characteristics and deaths in extended care are shown in Table 3. Deaths among older people were more likely to 
Table 2 Crude and adjusted associations between decedent characteristics and home death, British Columbia, Canada, 2004 to 2008

\begin{tabular}{|c|c|c|c|c|c|}
\hline Characteristic & Crude odds ratio & $95 \% \mathrm{Cl}$ & Adjusted odds ratio* & $95 \% \mathrm{Cl}$ & $P$ value \\
\hline Age (years) $<50$ & 1.87 & $1.78-1.96$ & 1.74 & $1.64-1.84$ & $<0.0001$ \\
\hline $50-59$ & 1.86 & $1.78-1.95$ & 1.75 & $1.66-1.83$ & $<0.0001$ \\
\hline $60-69$ & 1.45 & $1.39-1.52$ & 1.38 & $1.32-1.44$ & $<0.0001$ \\
\hline $70-79$ & 1.00 & - & 1.00 & - & - \\
\hline $80-89$ & 0.61 & $0.59-0.64$ & 0.66 & $0.63-0.68$ & $<0.0001$ \\
\hline$\geq 90$ & 0.37 & $0.35-0.39$ & 0.42 & $0.39-0.44$ & $<0.0001$ \\
\hline Sex - Female & 1.00 & - & 1.00 & - & - \\
\hline Male & 1.49 & $1.45-1.53$ & 1.16 & $1.12-1.19$ & $<0.0001$ \\
\hline Marital status - Married & 1.00 & - & 1.00 & - & - \\
\hline Never married & 1.51 & $1.44-1.57$ & 1.21 & $1.15-1.27$ & $<0.0001$ \\
\hline Widowed & 0.59 & $0.57-0.61$ & 0.97 & $0.93-1.01$ & 0.12 \\
\hline Other & 1.38 & $1.33-1.44$ & 1.18 & $1.13-1.23$ & $<0.0001$ \\
\hline Residence - Vancouver & 1.00 & - & 1.00 & - & - \\
\hline Victoria & 1.32 & $1.26-1.39$ & 1.43 & $1.36-1.51$ & $<0.0001$ \\
\hline Other city & 1.19 & $1.15-1.22$ & 1.17 & $1.13-1.21$ & $<0.0001$ \\
\hline Rural & 1.49 & $1.43-1.56$ & 1.32 & $1.26-1.38$ & $<0.0001$ \\
\hline Cause of death - Cancer & 1.00 & - & 1.00 & - & - \\
\hline Cardiovascular & 1.16 & $1.12-1.21$ & 1.56 & $1.51-1.62$ & $<0.0001$ \\
\hline Cerebrovascular & 0.26 & $0.24-0,28$ & 0.36 & $0.33-0.39$ & $<0.0001$ \\
\hline COPD & 0.62 & $0.57-0.67$ & 0.77 & $0.72-0.84$ & $<0.0001$ \\
\hline Pneumonia/Influenza & 0.26 & $0.23-0.29$ & 0.38 & $0.34-0.44$ & $<0.0001$ \\
\hline Dementia & 0.12 & $0.10-0.14$ & 0.20 & $0.18-0.23$ & $<0.0001$ \\
\hline Other & 0.95 & $0.92-0.99$ & 0.93 & $0.90-0.97$ & 0.0002 \\
\hline Year of death - 2004 & 1.00 & - & 1.00 & - & - \\
\hline 2005 & 0.98 & $0.94-1.03$ & 0.98 & $0.94-1.03$ & 0.43 \\
\hline 2006 & 0.96 & $0.92-1.00$ & 0.98 & $0.94-1.02$ & 0.32 \\
\hline 2007 & 0.94 & $0.90-0.98$ & 0.96 & $0.92-1.00$ & 0.06 \\
\hline 2008 & 0.91 & $0.87-0.95$ & 0.93 & $0.89-0.97$ & 0.002 \\
\hline
\end{tabular}

* Adjusted odds ratios obtained from logistic models that also controlled for place of birth.

occur in extended care, while males were less likely to die in extended care as compared with females. Analysis by marital status showed that deaths of married people were less likely to occur in extended care facilities in comparison with deaths of those never married or widowed. Deaths in Victoria and other urban areas were more likely to occur in extended care compared with deaths in Metro Vancouver, while deaths in rural areas were less likely to occur in extended care. Analysis by cause of death revealed that deaths from cardiovascular disease, cerebrovascular disease, COPD, pneumonia/influenza, and other causes were less likely to occur in extended care facilities as compared with cancer deaths but deaths due to dementia were much more likely to occur in extended care facilities. Deaths in extended care increased in frequency after 2004 (Table 3).

Table 4 provides the crude and adjusted associations between person characteristics and deaths in hospital. Deaths at the extremes of age were less likely to occur in hospital, while male deaths and deaths of married people were more likely to occur in hospital. Deaths outside Metro Vancouver were less likely to occur in hospital, whereas deaths due to cardiovascular disease, cerebrovascular disease, COPD, pneumonia/influenza, and other causes were more likely to occur in hospital as compared with cancer deaths. On the other hand, deaths from dementia were much less likely to occur in hospital compared with deaths from cancer. There was no significant 
Table 3 Crude and adjusted associations between decedent characteristics and death in an extended care facility, British Columbia, Canada, 2004 to 2008

\begin{tabular}{|c|c|c|c|c|c|}
\hline Characteristic & Crude odds ratio & $95 \% \mathrm{Cl}$ & Adjusted odds ratio* & $95 \% \mathrm{Cl}$ & $P$ value \\
\hline Age (years) $<50$ & 0.26 & $0.24-0.28$ & 0.29 & $0.26-0.31$ & $<0.0001$ \\
\hline $50-59$ & 0.50 & $0.47-0.53$ & 0.52 & $0.49-0.55$ & $<0.0001$ \\
\hline $60-69$ & 0.65 & $0.62-0.68$ & 0.66 & $0.63-0.69$ & $<0.0001$ \\
\hline $70-79$ & 1.00 & - & 1.00 & - & - \\
\hline $80-89$ & 1.94 & $1.89-2.01$ & 1.75 & $1.70-1.81$ & $<0.0001$ \\
\hline$\geq 90$ & 3.88 & $3.75-4.02$ & 3.31 & $3.19-3.45$ & $<0.0001$ \\
\hline Sex - Female & 1.00 & - & 1.00 & - & - \\
\hline Male & 0.51 & $0.50-0.52$ & 0.73 & $0.71-0.75$ & $<0.0001$ \\
\hline Marital status - Married & 1.00 & - & 1.00 & - & - \\
\hline Never married & 0.94 & $0.90-0.98$ & 1.58 & $1.50-1.66$ & $<0.0001$ \\
\hline Widowed & 2.57 & $2.50-2.64$ & 1.42 & $1.38-1.47$ & $<0.0001$ \\
\hline Other & 1.04 & $1-1.08$ & 1.35 & $1.30-1.41$ & $<0.0001$ \\
\hline Residence - Vancouver & 1.00 & - & 1.00 & - & - \\
\hline Victoria & 1.70 & $1.64-1.77$ & 1.59 & $1.53-1.66$ & $<0.0001$ \\
\hline Other city & 1.20 & $1.17-1.23$ & 1.22 & $1.18-1.26$ & $<0.0001$ \\
\hline Rural & 0.71 & $0.68-0.73$ & 0.80 & $0.76-0.83$ & $<0.0001$ \\
\hline Cause of death - Cancer & 1.00 & - & 1.00 & - & - \\
\hline Cardiovascular & 0.89 & $0.86-0.92$ & 0.53 & $0.51-0.54$ & $<0.0001$ \\
\hline Cerebrovascular & 1.47 & $1.41-1.53$ & 0.85 & $0.81-0.89$ & $<0.0001$ \\
\hline COPD & 0.94 & $0.88-0.99$ & 0.62 & $0.59-0.66$ & $<0.0001$ \\
\hline Pneumonia/Influenza & 1.55 & $1.45-1.65$ & 0.80 & $0.75-0.86$ & $<0.0001$ \\
\hline Dementia & 7.68 & $7.28-8.10$ & 3.91 & $3.69-4.13$ & $<0.0001$ \\
\hline Other & 0.64 & $0.62-0.66$ & 0.54 & $0.52-0.56$ & $<0.0001$ \\
\hline Year of death - 2004 & 1.00 & - & 1.00 & - & - \\
\hline 2005 & 1.03 & $0.99-1.07$ & 1.03 & $0.99-1.07$ & 0.14 \\
\hline 2006 & 1.17 & $1.13-1.21$ & 1.14 & $1.10-1.18$ & $<0.0001$ \\
\hline 2007 & 1.23 & $1.19-1.28$ & 1.22 & $1.17-1.26$ & $<0.0001$ \\
\hline 2008 & 1.11 & $1.07-1.15$ & 1.04 & $1.00-1.08$ & 0.06 \\
\hline
\end{tabular}

* Adjusted odds ratios obtained from logistic models that also controlled for place of birth.

change in the likelihood of death in hospital between 2004 and 2008, though there were fewer deaths in hospital in 2006 and 2007 as compared with 2004.

Table 5 shows the association between place of birth and place of death, with deaths of those born in Canada constituting the reference category. Deaths of people born in China and Hong Kong were less likely to occur at home, while deaths of those born in Europe and the USA were more likely to occur at home. Deaths of people born in India, China and the Philippines were significantly less likely to occur in extended care facilities. Finally, people born in China, India and the Philippines were more likely to die in hospital, while those born in Europe and the United States were less likely die in hospital as compared with people born in Canada.

\section{Discussion}

Our study showed that person characteristics such as age, gender, marital status, residence, cause of death and place of birth were significantly associated with place of death. For instance, age was a strong determinant of place of death, with younger people more likely to die at home and older people more likely to die in extended care. Males were less likely to die in extended care as compared with females and more likely to die at home or in hospital. Perhaps the most intriguing finding of our study was the association between place of birth and place of death; people born in Europe and the United states were more likely to die at home compared with those born in Canada, whereas those born in Asia were less likely to die at home and more likely to die in hospital. People born in 
Table 4 Crude and adjusted associations between decedent characteristics and death in hospital, British Columbia, Canada, 2004 to 2008

\begin{tabular}{|c|c|c|c|c|c|}
\hline Characteristic & Crude odds ratio & $95 \% \mathrm{Cl}$ & Adjusted odds ratio* & $95 \% \mathrm{Cl}$ & $P$ value \\
\hline Age (years) $<50$ & 0.49 & $0.47-0.51$ & 0.51 & $0.48-0.53$ & $<0.0001$ \\
\hline $50-59$ & 0.76 & $0.73-0.79$ & 0.75 & $0.72-0.79$ & $<0.0001$ \\
\hline $60-69$ & 0.93 & $0.90-0.97$ & 0.93 & $0.89-0.96$ & $<0.0001$ \\
\hline $70-79$ & 1.00 & - & 1.00 & - & - \\
\hline $80-89$ & 0.77 & $0.75-0.79$ & 0.85 & $0.82-0.87$ & $<0.0001$ \\
\hline$\geq 90$ & 0.47 & $0.45-0.48$ & 0.55 & $0.53-0.58$ & $<0.0001$ \\
\hline Sex - Female & 1.00 & - & 1.00 & - & - \\
\hline Male & 1.21 & $1.18-1.24$ & 1.05 & $1.03-1.07$ & $<0.0001$ \\
\hline Marital status - Married & 1.00 & - & 1.00 & - & - \\
\hline Never married & 0.55 & $0.53-0.57$ & 0.60 & $0.58-0.63$ & $<0.0001$ \\
\hline Widowed & 0.63 & $0.62-0.65$ & 0.73 & $0.71-0.75$ & $<0.0001$ \\
\hline Other & 0.70 & $0.68-0.72$ & 0.71 & $0.68-0.73$ & $<0.0001$ \\
\hline Residence - Vancouver & 1.00 & - & 1.00 & - & - \\
\hline Victoria & 0.54 & $0.52-0.56$ & 0.56 & $0.54-0.58$ & $<0.0001$ \\
\hline Other city & 0.73 & $0.72-0.75$ & 0.73 & $0.71-0.74$ & $<0.0001$ \\
\hline Rural & 0.89 & $0.86-0.92$ & 0.86 & $0.83-0.89$ & $<0.0001$ \\
\hline Cause of death - Cancer & 1.00 & - & 1.00 & - & - \\
\hline Cardiovascular & 0.91 & $0.89-0.94$ & 1.05 & $1.02-1.08$ & 0.004 \\
\hline Cerebrovascular & 1.22 & $1.17-1.27$ & 1.40 & $1.34-1.46$ & $<0.0001$ \\
\hline COPD & 1.36 & $1.29-1.44$ & 1.49 & $1.41-1.57$ & $<0.0001$ \\
\hline Pneumonia/Influenza & 1.14 & $1.07-1.22$ & 1.43 & $1.34-1.52$ & $<0.0001$ \\
\hline Dementia & 0.26 & $0.24-0.27$ & 0.31 & $0.29-0.33$ & $<0.0001$ \\
\hline Other & 1.02 & $0.99-1.05$ & 1.23 & $1.19-1.26$ & $<0.0001$ \\
\hline Year of death - 2004 & 1.00 & - & 1.00 & - & - \\
\hline 2005 & 0.98 & $0.95-1.02$ & 0.99 & $0.96-1.02$ & 0.58 \\
\hline 2006 & 0.91 & $0.88-0.94$ & 0.93 & $0.90-0.96$ & $<0.0001$ \\
\hline 2007 & 0.87 & $0.85-0.90$ & 0.89 & $0.86-0.92$ & $<0.0001$ \\
\hline 2008 & 0.97 & $0.94-1.00$ & 1.01 & $0.98-1.04$ & 0.61 \\
\hline
\end{tabular}

* Adjusted odds ratios obtained from logistic models that also controlled for place of birth.

China, India and the Philippines were less likely to die in extended care compared with those born in Canada.

The increased likelihood of males dying at home or in hospital has been described previously [5,11], although this finding has not been consistently observed in all settings [12]. Studies have shown that even among residents of nursing homes, males are more likely to die in hospital [13]. Our study shows that adjustment for potential confounders substantially attenuated the association between male gender and hospital death (crude odds ratio $1.21,95 \%$ CI $1.18-1.24$ versus adjusted odds ratio $1.05,95 \%$ CI $1.03-1.07)$. It is likely that the adjusted association is a product of residual confounding because of our use of broad age categories and potential misclassification of other factors. However, the association between male gender and increased home death and decreased death in extended care was stronger and likely represents a sociologic phenomenon.

Studies on cancer deaths show that such deaths are more likely to occur in hospital in both the big urban centres and in rural areas [14-16]. Although in our study $52.4 \%$ of cancer deaths occurred in hospital we noted that, relative to other causes of death (except deaths due to dementia), cancer patients were less likely to die in hospital.

In our study, deaths in Metro Vancouver were more likely to occur in hospital compared with deaths in Victoria and other urban areas, while deaths in rural areas were more likely to occur at home and less likely to occur in extended care or in hospital. These findings suggest that rural-urban differences may be due to a lesser degree of social support in urban centers $[17,18]$. Sparse research 
Table 5 Crude and adjusted odds ratios expressing the association between place of birth and place of death in British Columbia, 2004 to 2008

\begin{tabular}{|c|c|c|c|c|c|}
\hline $\begin{array}{l}\text { Place of death/ } \\
\text { Place of birth }\end{array}$ & $\begin{array}{l}\text { Crude odds } \\
\text { ratio }\end{array}$ & $95 \% \mathrm{Cl}$ & $\begin{array}{c}\text { Adjusted } \\
\text { odds ratio* }\end{array}$ & $95 \% \mathrm{Cl}$ & $\begin{array}{c}\mathrm{P} \\
\text { value }\end{array}$ \\
\hline \multicolumn{6}{|l|}{ Place of death: Home } \\
\hline Place of birth - Canada & 1.00 & - & 1.00 & - & - \\
\hline Europe & 0.91 & $0.88-0.94$ & 1.13 & $1.09-1.17$ & $<0.0001$ \\
\hline USA & 0.98 & $0.90-1.07$ & 1.12 & $1.03-1.23$ & 0.009 \\
\hline China & 0.51 & $0.46-0.56$ & 0.70 & $0.63-0.78$ & $<0.0001$ \\
\hline Hong Kong & 0.76 & $0.62-0.95$ & 0.73 & $0.59-0.91$ & 0.004 \\
\hline India & 0.94 & $0.85-1.04$ & 0.97 & $0.87-1.08$ & 0.56 \\
\hline Philippines & 0.89 & $0.74-1.08$ & 0.92 & $0.76-1.11$ & 0.43 \\
\hline Other & 1.05 & $0.98-1.12$ & 1.00 & $0.93-1.07$ & 0.94 \\
\hline \multicolumn{6}{|c|}{ Place of death: Extended care facility } \\
\hline Place of birth - Canada & 1.00 & - & 1.00 & - & - \\
\hline Europe & 1.22 & $1.19-1.25$ & 0.98 & $0.95-1.01$ & 0.25 \\
\hline USA & 1.15 & $1.08-1.24$ & 0.95 & $0.88-1.02$ & 0.19 \\
\hline China & 0.86 & $0.81-0.92$ & 0.79 & $0.74-0.85$ & $<0.0001$ \\
\hline Hong Kong & 0.77 & $0.65-0.91$ & 1.09 & $0.90-1.31$ & 0.39 \\
\hline India & 0.31 & $0.27-0.35$ & 0.35 & $0.31-0.40$ & $<0.0001$ \\
\hline Philippines & 0.55 & $0.46-0.65$ & 0.70 & $0.58-0.84$ & $<0.0002$ \\
\hline Other & 0.68 & $0.64-0.72$ & 0.85 & $0.80-0.91$ & $<0.0001$ \\
\hline \multicolumn{6}{|l|}{ Place of death: Hospital } \\
\hline Place of birth - Canada & 1.00 & - & 1.00 & - & - \\
\hline Europe & 0.97 & $0.94-0.99$ & 0.93 & $0.91-0.96$ & $<0.0001$ \\
\hline USA & 0.87 & $0.82-0.93$ & 0.91 & $0.85-0.97$ & 0.003 \\
\hline China & 1.69 & $1.59-1.80$ & 1.31 & $1.23-1.39$ & $<0.0001$ \\
\hline Hong Kong & 1.47 & $1.26-1.70$ & 1.14 & $0.98-1.33$ & 0.09 \\
\hline India & 2.07 & $1.91-2.24$ & 1.69 & $1.55-1.83$ & $<0.0001$ \\
\hline Philippines & 1.70 & $1.48-1.95$ & 1.35 & $1.17-1.56$ & $<0.0001$ \\
\hline Other & 1.24 & $1.18-1.31$ & 1.07 & $1.02-1.13$ & 0.01 \\
\hline
\end{tabular}

* Adjusted odds ratios obtained from logistic models which controlled for age, sex, marital status, residence, cause of death and year of death.

limits our understanding of these issues [19], although one possibility that cannot be excluded is the higher concentration of resource intense health services in urban areas and the consequent medicalization of death [20]. Access to home care services may also have an impact on location of death [21].

One of the most interesting findings of our study was the relationship between country of birth and place of death. The increased tendency of immigrants and, specifically, foreign born Asians to die in hospital has been noted in previous studies [1,2,22-28]. In our study, differences were observed in place of death preference among people with place of birth in China, India and the Philippines. These three population subgroups were more likely to die in hospital than people born in Canada. Whereas those born in China were less likely to die at home and extended care and more likely to die in hospital, people born in India and the Philippines were as likely as those born in Canada to die at home though not in extended care facilities. There is little information in the literature on the influence of place of birth and/or ethnicity on place of death. A study from California [23] showed that death in hospital was most common for Asian and Hispanic immigrants and least common for non-Hispanic whites and US-born Asians. Similarly, a study done on cancer patients in the United Kingdom [25] reported that Indian, Pakistani, Bangladeshi and Chinese patients were significantly more likely to die in 
hospital than White patients. A systematic review on minority ethnic groups and end of life care done in the United Kingdom [28] also showed that Asian patients with cancer were half as likely as non-Asians to die in a hospice, and that elderly Chinese expressed a preference for hospital care. The authors of these different studies have speculated that observed differences were due to cultural preferences, with reluctance among some immigrant subpopulations to utilize hospice services and complete advance directives.

Estimates such as those in our study could be used to inform public health policy and future resource allocation based on anticipated changes to population structure. This is a critical issue as the ageing of the Canadian population will increase the number of deaths per year substantially, with deaths in British Columbia likely to increase by $27 \%$ from 2004-08 levels by 2020 and by $50 \%$ by 2035 (assuming anticipated changes in population structure [29] and no change in age-specific death rates). Planning for health service delivery needs to account for such changes if resource allocation is to be appropriately directed at end of life services in the community, in extended care facilities and in hospital. For instance, anticipated increases in the absolute number and proportion of elderly decedents, implies a greater need for extended care facilities, given the place of death patterns observed in our study. Similarly, with immigration expected to account for $77.4 \%$ of increase in population by 2036 [29], place of birth considerations may be helpful in terms of anticipating demand for end of life services in specific locales.

Our study was based on data abstracted from death registrations which may have some inaccuracies related to the location of death, marital status and single coded underlying cause of death. The usage of postal codes to delineate urban and rural areas represents a standard method of classifying residence status but may not be completely accurate. Place of birth is not an exact determinant of ethnicity but is a pragmatic alternative that is both relevant and informative in this context. Finally, our study was descriptive and focused on where people died and not what kind of services they received as we did not have access to data about end of life services. Location of death should not be used as proxy for the extent of community-based resources as the final location of death may not necessarily be the location of care during most of the end of life [30].

\section{Conclusions}

In summary, our study shows that age, sex, marital status, rural versus urban residence, cause of death and place of birth are significant determinants of death at home, in extended care facility or in the hospital. The findings of our study can be used for the rational and knowledgebased allocation of health care resources including those required for hospital, extended care and community services at the end of life.

\section{Abbreviations \\ Cl: Confidence Intervals; Vs: Versus; ICD: International Classification of Diseases; USA: United States of America; COPD: Chronic Obstructive Pulmonary Disease; BC: British Columbia.}

\section{Competing interests}

The authors declared that they have no competing interest.

\section{Authors' contributions}

Both authors contributed equally to conception, design, analysis and interpretation of data. The manuscript was drafted by $J$ J and approved by KSJ. Both authors read and approved the final manuscript.

\section{Acknowledgements}

This study was supported by a Research Award from the BC College of Family Physicians.

K.S. Joseph is supported by a career award from the Child and Family Research Institute and a Chair award from the Canadian Institutes of Health Research.

\section{Author details}

'Division of Palliative Care, Department of Family Medicine, University of British Columbia, Vancouver, BC, Canada. ${ }^{2}$ School of Population and Public Health and the Department of Obstetrics and Gynaecology, University of British Columbia, Vancouver, BC, Canada. ${ }^{3}$ Vancouver General Hospital, 899 12th Avenue W, Vancouver, BC V5Z 1M9, Canada.

Received: 4 September 2012 Accepted: 25 April 2013

Published: 1 May 2013

\section{References}

1. Wilson DM, Northcott HC, Truman CD, Smith SL, Anderson MC, Fainsinger RL, Stingl MJ: Location of death in Canada: a comparison of 20th century hospital and non hospital location of death and corresponding trends. Eval Health Prof 2001, 24:385-403.

2. Wilson DM, Truman CD, Thomas R, Faisinger R, Kovacs-Burns K, Froggart K, Justice C: The rapidly changing location of death in Canada, 1994-2004. Soc Sci Med 2009, 68:1752-1758.

3. Death related statistics: Annual Report 2009. British Columbia: Vital Statistics Agency; 2012. (http://www.vs.gov.bc.ca/stats/annual/2009/pdf/deaths.pdf) Accessed May 5

4. Wilson DM, Smith SL, Anderson MC, Northcott HC, Fainsinger RL, Stingl MJ, Truman CD: Twentieth-century social and health-care influences on location of death in Canada. Can J Nurs Res 2002, 34:141-161.

5. Canadian Institute for Health Information: Health care Use at the End of life in Western Canada. Ottawa: Canadian Institute for Health Information; 2007.

6. Canadian Institute for Health Information: Health care Use at the End of life in British Columbia. Ottawa: Canadian Institute for Health Information; 2008.

7. Cohen J, Bilsen J, Hooft P, Deboosere P, van der Wal G, Deliens L: Dying at home or in an institution. Using death certificates to explore the factors associated with place of death. Health Policy 2006, 78:319-329.

8. Miettinen $O S$, Wang J: An alternative to the proportionate mortality ratio. Am J Epidemiol 1982, 114:144-148.

9. Miettinen OS: Estimability and estimation in case-referent studies. Am J Epidemiol 1976, 103:226-235.

10. Bow JD, Waters NM, Faris PD, Seidel JE, Galbraith D, Knudtson ML, Ghali WA, and the APPROACH Investigators: Accuracy of postal code coordinates as a proxy for location of residence. Int J Health Geogr 2004, 3:5.

11. Motiwala SS, Croxford R, Guerriere DN, Coyte PC: Predictors of place of death for seniors in Ontario: a population-based cohort analysis. Can J Aging 2006, 25:363-371.

12. Masucci L, Guerriere DN, Cheng R, Coyte PC: Determinants of place of death for recipients of home-based palliative care. J Palliat Care 2010, 26:279-286

13. McGregor MJ, Tate RB, Ronald LA, McGrail KM: Variation in site of death among nursing home residents in British Columbia, Canada. J Palliat Med 2007, 10:1128-1136. 
14. Burge F, Lawson B, Johnston G: Trends in the place of death of cancer patients, 1992-1997. CMAJ 2003, 168:265-270.

15. Burge $F$, Lawson B, Johnston G: Where a cancer patient dies: the effect of rural residency. J Rural Health 2005, 21:233-238.

16. Barroetavena M, Regier M, Zamar R: Spatial and temporal trends in location of death for rural and remote British Columbia patients [abstract]. J Palliat Care 2006, 22:242.

17. Houttekier D, Cohen J, Bilsen J, Addington-Hall J, Onwuteaka-Philipsen B, Deliens L: Place of death in metropolitan regions: Metropolitan versus non-metropolitan variation in place of death in Belgium, Netherlands and England. Health Place 2010, 16:132-139.

18. Houttekier D, Cohen J, Bilsen J, Deboosere P, Verduyckt P, Deliens L: Determinants of place of death in the Brussels metropolitan region. J Pain Symptom Manage 2009, 37:996-1005.

19. Robinson CA, Pesut B, Bottorff JL, Mowry A, Broughton S, Fyles G: Rural palliative care: a comprehensive review. J Palliat Med 2009, 12:253.

20. Tang ST, Huang E-W, Liu T-W, Rau K-M, Hung Y-N, Wu S-C: Propensity for home death among Taiwanese cancer decedents in 2001-2006, determined by services received at end of life. J Pain Symptom Manage 2010, 40:566-574

21. Brackley ME, Penning MJ: Home-care utilization within the year of death: trends, predictors and changes in access equity during a period of health policy reform in British Columbia, Canada. Health Soc Care Community 2009, 17:283-294.

22. Regier MD: Does culture affect the location of death among cancer patients in British Columbia: a pilot study utilizing standard and novel statistical methods in End-of-life research. Masters Thesis: University of British Columbia; 2005. Accessed at https://circle.ubc.ca/handle/2429/16679.

23. Lackan NA, Eschbach K, Stimpson JP, Freeman JL, Goodwin JS: Ethnic differences in in- hospital place of death among older adults in California. Med Care 2009, 47:138-145.

24. Coupland VH, Madden P, Jack RH, Moller H, Davies EA: Does place of death from cancer vary between ethnic groups in South East England? Palliat Med 2011, 25(4):314-322

25. Johnson KS, Kuchibhatala M, Sloane RJ, Tanis D, Galanos AN, Tulsky JA: Ethnic differences in the place of death of elderly hospice enrollees. J Am Geriatr Soc 2005, 53:2209-2215.

26. Gruneir A, Mor V, Weitzen S, Truchil R, Teno J, Roy J: Where people die. A multilevel approach to understanding influences on site of death in America. Med Care Res Rev 2007, 64:351-378.

27. Worth A, Irshad T, Bhopal R, Usher BJ, Brown D, Lawton J, Grant E, Murray S, Kendall M, Adam J, Gardee R, Sheikh A: Vulnerability and access to care for South Asian Sikh and Muslim patients with life limiting illness in Scotland: prospective longitudinal qualitative study. BMJ 2009, 338:b183. doi:10.1136/bmj.b183.

28. Evans N, Menaca A, Andrew EWW, Koffman J, Harding R, Higginson IJ, Pool R, Gysels M, on behalf of PRISMA: Systematic review of the primary research on minority ethnic groups and end of life care from the United Kingdom. J Pain Symptom Manage 2012, 43:261-286.

29. Overview of the $B C$ and regional population projections. British Columbia. http://www.bcstats.gov.bc.ca/StatisticsBySubject/Demography/ PopulationProjections.aspx Accessed May 5, 2012.

30. Lawson BJ, Burge Fl: Re-examining the definition of location of death in health services research. J Palliat Care 2010, 26:202-204.

\section{Submit your next manuscript to BioMed Central and take full advantage of:}

- Convenient online submission

- Thorough peer review

- No space constraints or color figure charges

- Immediate publication on acceptance

- Inclusion in PubMed, CAS, Scopus and Google Scholar

- Research which is freely available for redistribution

Submit your manuscript at www.biomedcentral.com/submit 